\title{
Fine Mining Technology for High Water Cut Reservoir
}

\author{
Lijia Song ${ }^{1}$, Liyang Song ${ }^{2}$ and Jiwei Wang ${ }^{1}$
}

\author{
1 Key Laboratory of Enhanced Oil Recovery, Ministry of Education, Northeast Petroleum University, \\ Daqing, Heilongjiang, 163318, China;
}

2 Petroleum Exploration and Development Research Institute, SINOPEC, Beijing, 100083, China

\begin{abstract}
Keyword: Separated layer water flooding; Production forecast; Drilling tech; Inverted nine spot water flooding pattern; Remaining oil
\end{abstract}

\begin{abstract}
The oil production rate is slow in Oilfield, Low recovery degree, the difficulty of improving oil recovery by chemical flooding. Combined with formation heterogeneity characteristics and production dynamic situation, according to the distribution characteristics of remaining oil, adopting new drilling and Fine stratified water flooding technology. The region with high thickness of selected oil layer and high residual oil content is deployed to deployment the completely penetrating well and the infill well, straight well taking into account two layers, horizontal well is based on single layer, Fine layered inverted nine spot water flooding pattern development. After the implementation of newly drilled well, perforations adding, fracturing and separated layer water flooding, The predicted oil field has add up 1286.98 million tons of oil production by 2035 , ultimate recovery factor $33.78 \%$, water ratio $97 \%$, the formation pressure is always between 18 and $19 \mathrm{MPa}$,the whole effect is better.

At present, most oilfields at home and abroad have entered the later stage of development, The comprehensive water ratio of oil field is high, oil recovery rate is slow, The degree of reserve recovery is generally low. In view of oilfield development, Due to environmental protection and the development of economic costs and other reasons, It is not effective to carry out chemical flooding to improve oil recovery ratio. Large displacement liquid extraction technology can improve oil production rate to a certain extent. However, the processing cost of produced liquid is higher, bailing oil recovery technique can reduce the cost of mining, but the oil recovery rate is slow, the economic benefits are not good. In this paper, combined with formation heterogeneity characteristics and production dynamic situation, developing new drilling and fine layered water injection technology. It can effectively improve oilfields recovery ratio, yield prediction is better, the overall benefit is considerable.
\end{abstract}

\section{Reservoir Status}

The reservoir is located in the Middle Jurassic strata, lithology is a sandstone, argillaceous sandstone and siltstone dominated sandstone, most of the particles are turbinate and semicircular particles, the main reservoir bed include 5\# and 6\# layers, the interlamination interlayer is obvious. The buried depth of the reservoir bed is about $2100 \mathrm{~m}$,the formation thickness is between 26 and $45 \mathrm{~m}$, simple anticline structure, the faults are agenesis, The effective thickness of reservoir bed is between 5 and $15 \mathrm{~m}$, porosity averaged 0.2 , the mean permeability is $86 \mathrm{mD}$. in layer heterogeneity is powerful, the coefficient of permeability variation was 0.91 . The initial formation pressure is $18 \mathrm{MPa}$, the petroleum pool temperature is $68^{\circ} \mathrm{C}$, the formation water salinity is higher.

The oil field has been put into development for more than 50 years, current nissan oil 460t, the composite water cut is $92 \%$, cumulative oil production of 728 million tons, the degree of reserve recovery is $18.6 \%$, the recovery rate of recoverable reserves is estimated to be $45 \%$. Comprehensive analysis of the oil field shows that the oil well pattern is not perfect, the comprehensive recovery degree is low, and the water content is generally high. 


\section{Adjustment Scheme}

Production Analysis of Input Well. In recent years, the oil field shows that the wells with daily production of more than 10 tons in the new production well account for $28 \%$ of the total number of newly put into production wells,

the Wells that produce the oil between 5 and 10 tons of oil account for $18 \%$ of the new total well, the Wells that produce the oil between 1 and 5 tons of oil account for $46 \%$ of the new total well, wells with daily production of less than 1 tons account for $8 \%$ of the total number of newly put into production wells. The average daily oil production of the new well is $8.26 \mathrm{t}$, and the average water content is $58 \%$, the effect is better, which laid a good foundation for the adjustment of the new well. As a whole, horizontal well integrated moisture content is lower than straight well, and the yield of single well is obviously increased, and the horizontal well advantage is obvious, indicating the direction for the new well deployment, see Table 1

Table 1 Data comparison between horizontal and vertical wells

\begin{tabular}{|c|c|c|c|c|c|c|}
\hline \multirow{2}{*}{$\begin{array}{c}\text { Nissan oil } \\
(\mathrm{t})\end{array}$} & $\begin{array}{c}\text { Well } \\
\text { number } \\
\text { ratio } \\
(\%)\end{array}$ & $\begin{array}{c}\text { Single well } \\
\text { oil } \\
\text { production } \\
(\mathrm{t})\end{array}$ & $\begin{array}{c}\text { Water } \\
\text { percentage } \\
(\%)\end{array}$ & $\begin{array}{c}\text { Well } \\
\text { number } \\
\text { ratio } \\
(\%)\end{array}$ & $\begin{array}{c}\text { Single well } \\
\text { oil } \\
\text { production } \\
(\mathrm{t})\end{array}$ & $\begin{array}{c}\text { Water } \\
\text { percentage } \\
(\%)\end{array}$ \\
\hline$>10$ & 58 & 22.0 & 18 & 20 & 19 & 26 \\
\hline $5 \sim 10$ & 14 & 6 & 21 & 20 & 8 & 43 \\
\hline $1 \sim 5$ & 26 & 3 & 81 & 46 & 3.2 & 82 \\
\hline$<1$ & 2 & 0.6 & 95 & 14 & 0.5 & 94 \\
\hline Total & 100 & 14.24 & 35.32 & 100 & 6.94 & 64.68 \\
\hline
\end{tabular}

Fine Stratified Water Flooding Technology. Reservoir water drive use degree is low, the reservoir has high longitudinal heterogeneity, experiencing long term water flooding, the water injection is obvious in single or high permeable layer, early ten annual water absorption profiles show that the longitudinal reserves of reservoirs vary greatly, range from 24.4 to $93.7 \%$, with an average of about $43 \%$.The water injection profile of individual injection wells shows that the difference of water absorption between layers is obvious due to general flooding, the internal water out is uneven, and some of the target layers are completely non absorbent. See Fig 1.Therefore, it is necessary to implement separate layer water injection to improve reservoir production.

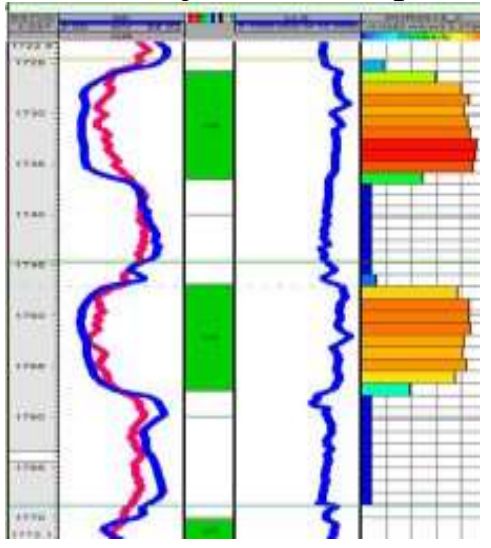

Figure 1. water injection profile

Based on the description of the remaining oil distribution characteristics, the author makes a targeted excavation and adjustment measures based on the influence factors of remaining oil, as 
shown in table 2.

Table 2 Adjustment table for remaining oil production

\begin{tabular}{|c|c|c|c|}
\hline Type & Remaining oil & Influence factor & Adjustment scheme \\
\hline \multirow{2}{*}{$\begin{array}{l}\text { Horizontal } \\
\text { plane }\end{array}$} & imperfect well pattern & $\begin{array}{l}\text { imperfect well } \\
\text { pattern }\end{array}$ & perfect well pattern \\
\hline & $\begin{array}{l}\text { regions with strong } \\
\text { heterogeneity }\end{array}$ & $\begin{array}{c}\text { reservoir } \\
\text { heterogeneity }\end{array}$ & $\begin{array}{l}\text { Down flow well profile control、 oil well } \\
\text { fracturing }\end{array}$ \\
\hline \multirow{3}{*}{$\begin{array}{l}\text { Machine } \\
\text { direction }\end{array}$} & microstructural high & structure & vertical Well encryption \\
\hline & vertical heterogeneity & $\begin{array}{c}\text { reservoir } \\
\text { heterogeneity }\end{array}$ & $\begin{array}{l}\text { Bottom profile control and water shutoff, } \\
\text { middle and upper part perforations adding }\end{array}$ \\
\hline & $\begin{array}{c}\text { imperforated } \\
\text { stratigraphic position }\end{array}$ & perforation & completeness perforation \\
\hline
\end{tabular}

Scheme deployment fully combines numerical modeling with reservoir engineering analysis results and production trends, Optimizing the completely penetrating well and infill well in areas deploy with large reservoir thickness and high remaining oil abundance, The vertical well takes into account two layers, and the horizontal well is based on single layer, Taking full advantage of deep well area data, the well location of the deployed well is finally determined to improve the economic efficiency of the adjustment well, The development mode still adopts low cost water injection development mode, inverted nine spot water flooding pattern, the well spacing is about $330 \mathrm{~m}-410 \mathrm{~m}$.

\section{Yield prediction}

The geological model of the block is established and the historical fitting is carried out, and the production prediction is carried out on the basis of the model. See Fig 2 and 3 .During the prediction, the injection production ratio of the reservoir is kept at 1 1.2, the old well Keep the old history fitting to predict production, New drilling flow pressure production, the minimum bottom hole flow pressure is not less than $13 \mathrm{Mpa}$, shut in well when water content is greater than $98 \%$ or daily oil is lower than $1 \mathrm{t}$. The maximum bottom hole flow pressure limit of injection well is $25 \mathrm{Mpa}$.

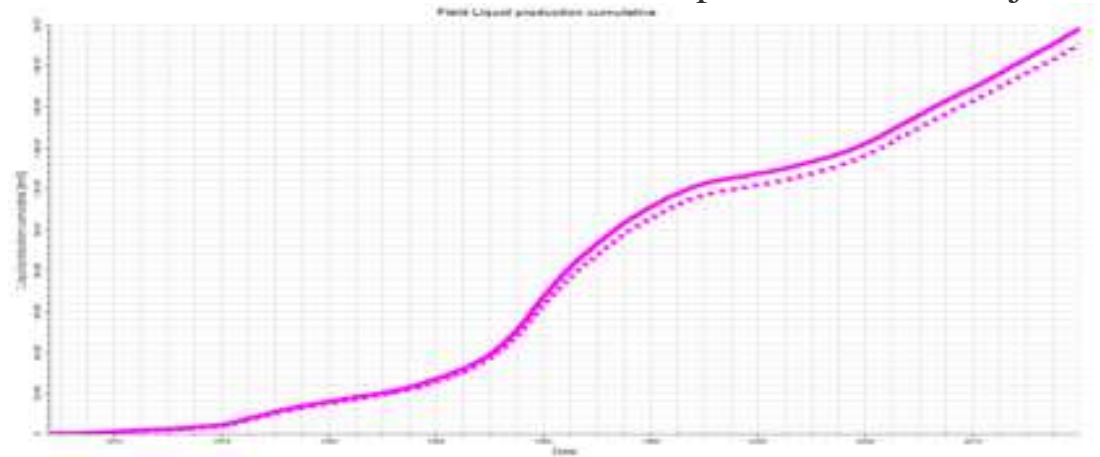

Figure 2. Reservoir history matching 


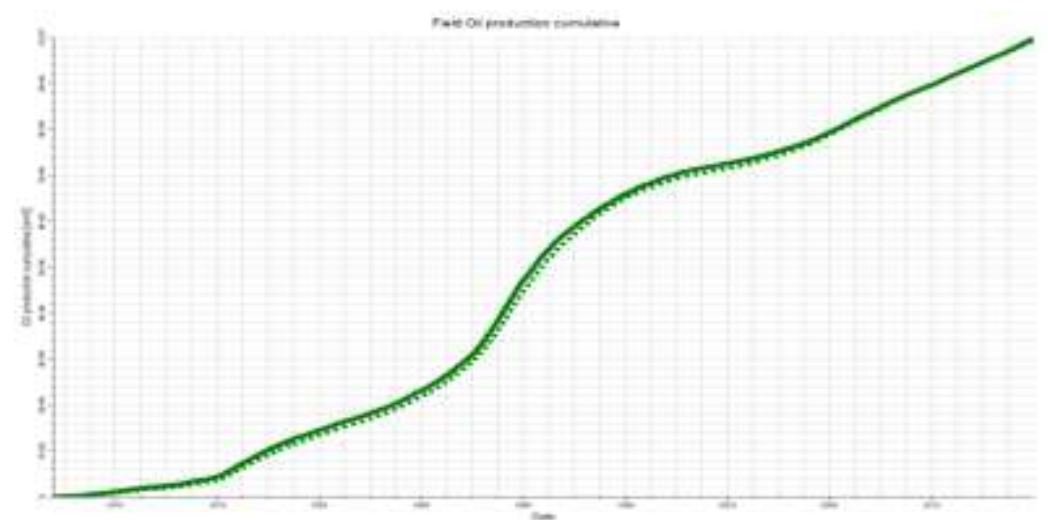

Figure 3. Reservoir history matching

In the new drilling, back layer, perforations adding, fracturing and layered water flooding development, the annual oil production in reservoir increases rapidly, and then enters the decline stage. Reservoir numerical simulation predicts that the total oil production will be 1286.95 million tons and 500 tons by 2035 .Finally, the degree of reserve recovery is $33.78 \%$, and the water content ratio is $91.4 \%$, The formation pressure is always maintained between 18 and $19 \mathrm{MPa}$, and the overall effect is preferably.

\section{Conclusion}

Through the analysis of input Wells, points out the direction for the new well deployment.

Through the fine stratified water flooding technology, distribution and mining of remaining oil to make adjustments, thus developed for remaining oil tapping the minute hand of policy.

It predicts that the oil field will produce 1286.95 million tons of oil in 2035, and the degree of reserve recovery is $33.78 \%$

\section{Acknowledgements}

This work is supported by National Science and Technology Major Project of China (No. 2016ZX05010003 and No. 2016ZX05025003) and Northeast Petroleum University Innovation Foundation for Postgraduate (YJSCX2016-007NEPU).

\section{Reference}

[1] Gao L, Xian Shiyou University. Layered water injection technology application[J]. Petrochemical Industry Technology, 2016.

[2] Huo A. Integrated Application of Reservoir Performance Analysis and Layered Water Injection Technology in Block Li 8[J]. Journal of Yangtze University, 2015.

[3] Wang Jianhua, Sun Dong, Li Heyi, et al. Study and application of fine stratified waterflooding technology [J]. Well Testing, 2011, 20 (4): 41-44.

[4] Zhi-Wei W U. Experimental Research and Potential Evaluation about Remaining Oil Distribution after Water Flooding in Heterogeneous Reservoir[J]. Science Technology \& Engineering, 2017.

[5] Du Q, Zhao Y, Lu Y, et al. Study on Genetic Type and Potential Tapping Measures of the Remaining Oil in Multi-layered and Heterogeneous Sandstone Reservoir[J]. Journal of Dermatologic Surgery \& Oncology, 1999, 17(11):865-868.

[6] Zhi-Wei W U, Yang Z P, Wang G Y, et al. Experimental Study on Oil Production Characteristics of Water Flooding and Remaining Oil Distribution in the Oilfield of Plain Heterogeneity[J]. Science Technology \& Engineering, 2016. 